\title{
Unilaterally Extended Thoracoscopic Thymectomy: The Right Side or the Left Side Approach
}

\author{
Victor Tomulescu \\ Fundeni Clinical Institute, Center of General Surgery \\ and Liver Transplant "Dan Setlacec" \\ Romania
}

\section{Introduction}

Myasthenia gravis (MG) is a heterogeneous disorder with a protean, clinical, pathologic, and immunobiological picture(Beekman, Kuks, and Oosterhuis 1997, 244:112-118) Myasthenia gravis (MG) is the best studied and understood autoimmune disease. The autoimmune origin of the disease was suggested for the first time by Simpson (Simpson 1982, 226:1045-1050), but Almon and colleagues(Almon and Appel 1976, 274:235-243) were the first to demonstrate circulating antibodies to acetylcholine receptor (AchR) sites of the neuromuscular junction. Elevated antibody levels are found in approximately $90 \%$ of patients and are roughly correlated with the clinical severity of the disease(Beekman, Kuks, and Oosterhuis 1997, 244:112-118). As Lennon (Lennon, Lindstrom, and Seybold 1976, 274:283-299) showed, the thymus is evidently implicated in the production not only of these end-plate antibodies but also to striated muscle antibodies through some aberration in its normal function.

In most cases, the target of the autoimmune attack is the nicotinic acetylcholine receptor (AChR) located in the postsynaptic muscle endplate membrane. AChR antibodies produce deficient neuromuscular transmission by three different mechanisms:

- they bind to the AChR and alter function;

- they promote endocytosis and accelerate the degradation rate of AchR

- antibodies activate complement leading to destruction of the postsynaptic surface(Hughes, Moro De Casillas, and Kaminski 2004, 24:21-30).

Other neuromuscular junction antigens, distinct from AChR, also play a role in autoimmune attack of patients with MG. Up to $20 \%$ of patients with generalized MG are seronegative for AChR antibodies with $30 \%$ of these patients having autoantibodies directed against a distinct endplate membrane intrinsic protein, muscle-specific receptor tyrosine kinase (MuSK) (Evoli et al. 2003, 126:2304-2311). Some MuSK antibodies compromise AChR channel function, but specific pathogenic mechanisms have not been defined. One would predict that MuSK antibodies compromise neuromuscular transmission by affecting AChR clustering at the neuromuscular jonction. Patients who have late onset non-tumoral MG may also have tintin 
(an intracellular muscle protein) and ryanodine receptor antibodies, the presence of these antibodies being associated with a worse prognosis (Romi, Gilhus, and Aarli 2006, 183:24-25).

The thymus plays a key role in tolerance induction to self-antigens and in responsiveness of lymphocytes to foreign antigens. Several findings indicate that the thymus is involved in MG pathogenesis:

- Pathological changes, like lymphoid follicular hyperplasia or thymomas, are frequent in patients with MG.

- $\quad$ MG thymic tissue contains abnormally elevated amounts of mature T cells, most of them AChR-reactive T cells(Sommer et al. 1990, 28:312-319;Sommer, Tackenberg, and Hohlfeld 2008, 91:169-212).

- myasthenic thymic tissue fragments transplanted to severe combined immunodeficiency mice produce human antibodies, which bind to the AChR(Schonbeck et al. 1992, 90:245-250).

Most myasthenic thymuses contain B cells capable of producing AchR antibodies, particularly those hyperplastic thymuses with germinal centers(Leite et al. 2007, 171:893905). Normal and myasthenic human thymuses express gene transcripts and epitopes of all AchR As subunits(Navaneetham et al. 2001, 24:203-210).

The availability of AChR in thymus may play a role in pathogenesis of MG. It is considered that the AChR expressed on thymic myoid cells is the original auto-sensitizing antigen, and the thymic changes in MG are primary events in the autoimmune pathogenesis of the disease(Leite, Jones, Strobel, Marx, Gold, Niks, Verschuuren, Berrih-Aknin, Scaravilli, Canelhas, Morgan, Vincent, and Willcox 2007, 171:893-905). It is possible that the myoid cells to be altered by viral illness involving the thymus and the proximity to antigen presenting cells and helper T-cells to facilitate the abnormal immunologic response(Drachman 1994, 330:1797-1810).

Patients with MG have frequently other immune-mediated diseases like rheumatoid arthritis, lupus, Graves' disease, tyroiditis and a family history of autoimmune disorders. That imposed the study of the genetic factor implication in MG. HLA types like HLA-B8, DRw3, Dqw2 have been associated with AChR antibody positive MG and haplotypes DR14 and DQ5 with MuSK antibody positive MG(Carlsson et al. 1990, 31:285-290;Niks et al. 2006, 66:1772-1774).

Since the first case reported by Schumacher and Roth in 1913 (Keesey 2004, 24:5-16), the role of thymectomy in MG treatment has been well established. The main study demonstrating the benefit of thymectomy in MG was that of Buckingham and associates(Buckingham et al. 1976, 184:453-458), who compared the clinical course of patients after thymectomy with a computer-matched cohort receiving medical therapy. The best assessment of potential benefits of thymectomy in modern era comes from a review of 21 controlled but nonrandomized studies(Gronseth and Barohn 2000, 55:7-15) showing that patients undergoing thymectomy were twice as likely to achieve medication-free remissions.

\section{Indication (thymectomy in the multimodal treatment of MG)}

The major issues for a surgeon who has an interest in thymectomy are related to patient selection and surgical technique. Regarding patient selection, decision should be taken in 
cooperation with the neurologist that supervised the treatment. Coordinated and strong multidisciplinary collaboration among neurologists, surgeons and anaesthesiologists is mandatory in making appropriate decisions regarding patient selection, therapeutic options and the timing of surgery.

There is a current consensus that a patient with generalized non-tumoral MG who is between puberty and 60 years of age should undergo surgery, but the optimal approach is still under debate(Toyka KV and Gold R 2007, 158:309-321). Surgery for patients older than 60 years is controversial. In patients with ocular myasthenia the benefit is uncertain (Bulkley et al. 1997, 226:324-334;Guillermo et al. 2004, 109:217-221)

Nowadays surgical procedures for thymectomy in non-tumoral MG comprise transternal, transthoracic, transcervical, subxifoidian or thoracoscopic thymectomy. The primary goal of every technique, of every surgeon doing thymectomy is "to remove as much thymus and ectopic thymus as possible"(Rubin 2006, 82:1007-1008). An optimal approach should combine least invasiveness and maximal radicality.

This is related with Jaretski's (Jaretzki, Steinglass, and Sonett 2004, 24:49-62;Jaretzki, III and Wolff 1988, 96:711-716) now classic point of view in relation to thymus anatomy: that the main body of the gland, incapsulated consisting in a right and a left lobe that join at their central portion just caudal to the left innominate vein, is accompanied with small extracapsular foci of thymic tissue distributed widely in mediastinal and cervical adipose tissue. This is the reason why the surgical technique consists in rigorous emptying of the anterior mediastinum from diaphragm to the cervical area, between the phrenic nerves, of all thymus and fatty tisuue. Advantages of thoracoscopic thymectomy besides minimizing the trauma and undoubted cosmetic advantages consist in the exceptional intraoperative overview (the new high definition cameras make these images even more accurate) that make the procedure safer, and diminishing the risk of injury of fine structures not related with the procedure.

The diagnosis of myasthenia gravis is based on the patient's history, physical examination, positive response to anticholinesterase agents and electrophysiology studies. Preoperative diagnostic tests should include spirometry and a CT scan. The immunologic profile with AchR antibodies assay and anti-MuSK antibody should be performed on all patients. Thymectomy should be performed when MG is in a stable condition; there is no indication for "emergency operation". Al the patients should be well prepared for the intervention. In our experience patients were considered suitable for a surgical procedure only when evidence showed good treatment tolerance and a decrease of the quantitative myasthenia gravis score (Myastenia Gravis Foundation of America (MGFA) recommendations for clinical research standards (Jaretzki, III et al. 2000, 70:327-334)) to at least 10 points.

Unilaterally extended thoracoscopic thymectomy is performed with the patient under general anesthesia with double-lumen tube placement and lying in a $15-30^{\circ}$ off-centre position (fig1).

Choice of the side is matter of training, mentoring, safe complete removal of the thymus and peri-thymic fatty tissue from diaphragm to cervical area being the main goal. A versatile thoracic surgeon should be able to approach the thymus by a variety of methods and if a left side approach is not possible due to previous thoracotomy for example, a right side approach should be performed with the same dexterity, safety and preciseness. 


\section{Left side approach or right side approach}

Three or four trocars are inserted into the left hemithorax. The operator stays on the left side of the patient in a caudal position to the cameraman, but these positions are not fixed and any improvement in better ergonomics or superior visualization should be taking into account. The monitor is on the right side of the patient. The first trocar $(10-12 \mathrm{~mm})$ is placed through the fifth or sixth intercostal space, between the middle and posterior axillar lines.

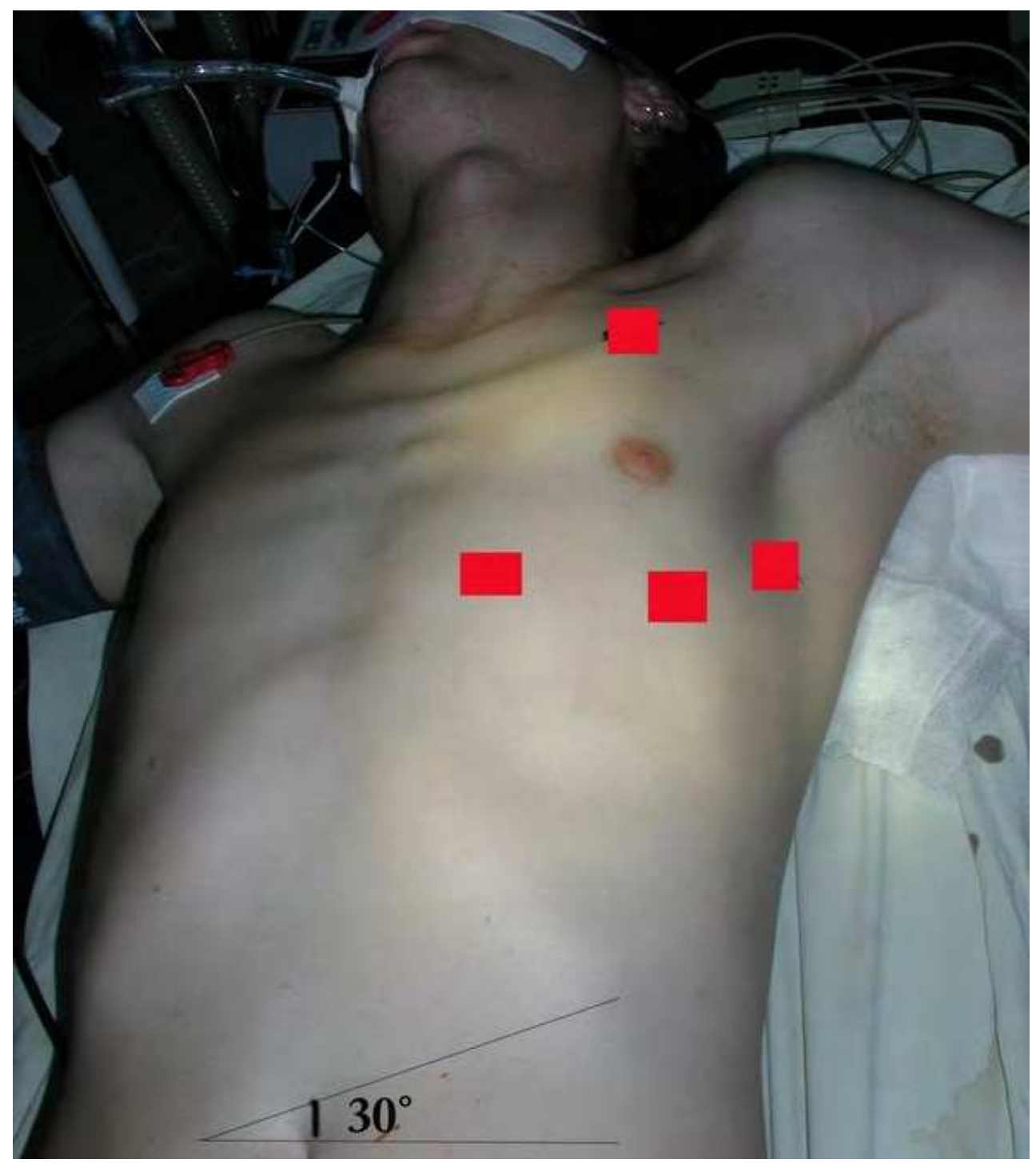

Fig. 1. Patient and trocar positioning 
Pleural cavity exploration is facilitated by the selective right bronchus intubation and by $\mathrm{CO}_{2}$ insufflations at a maximum of $10 \mathrm{mmHg}$ pressure (fig2).
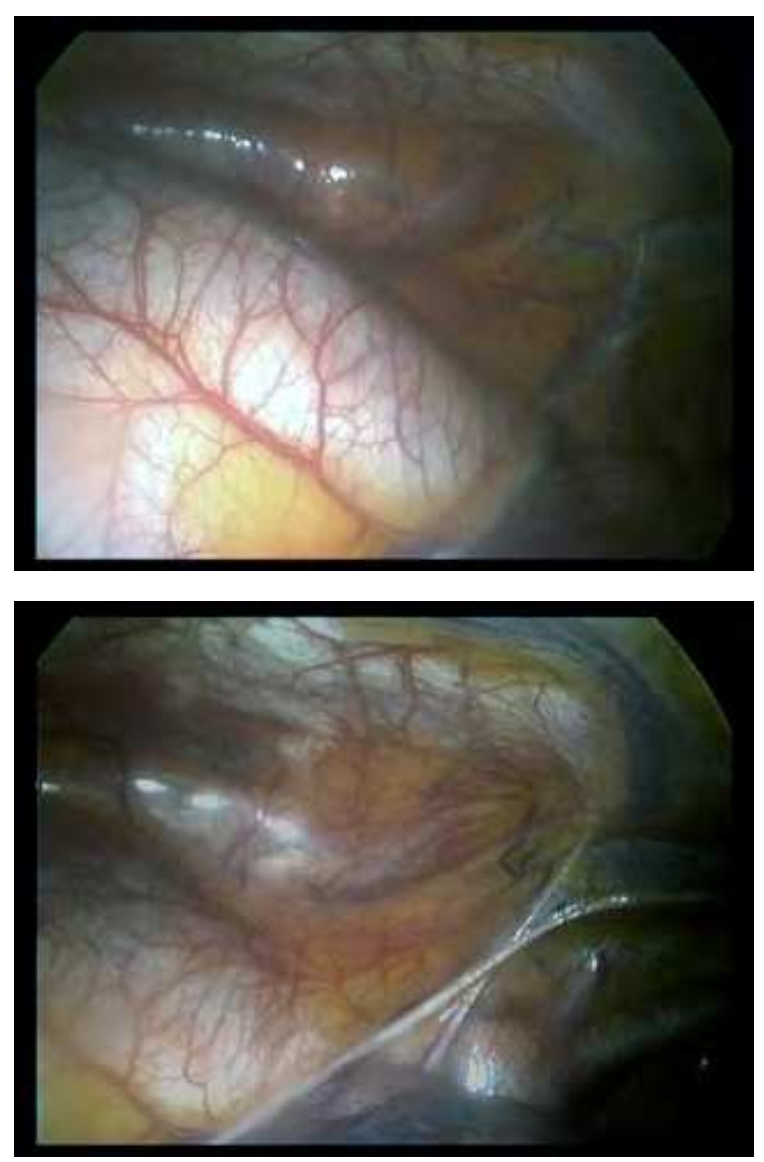

Fig. 2. $\mathrm{CO}_{2}$ insufflations at a maximum of $10 \mathrm{mmHg}$ pressure enlarge the anterior mediastinum space

The second and third trocars (10-12 and 5-7 $\mathrm{mm}$ or $10-12 \mathrm{~mm}$, respectively) are placed through the third inter-costal space on the anterior axilary line and through the fourth or fifth inter-costal spaces on the mid-clavicle line. For females the incision should be done keeping in mind the important cosmetic problem of the peri -mammary scars.

After a careful pleural cavity exploration we spot the anterior mediastinum. The capnotorax helps us also in the dissection. In order to have this support we need to start all the operations with incision of the mediastinal pleura along the two important landmarks of thymectomy: the phrenic nerve and the internal thoracic artery (fig3), allowing the gas dissection to help us. 
The incision of the mediastinal pleura and the dissection of the thymus begin anterior to the left phrenic nerve and continue into the entire thymus compartment. The use of the ultrascision scalpel (Harmonic Scalpel Ultrascision; Ethicon Endo-Surgery) facilitates the dissection, decreases the time of the intervention, and avoids the risks of the electrocoagulation in this area. The cranial limit of the dissection, at the level of the mediastinal pleura, is the internal thoracic artery. The operation continues with dissection of the inferior left thymic horn and pericardial fatty tissue (fig 4).

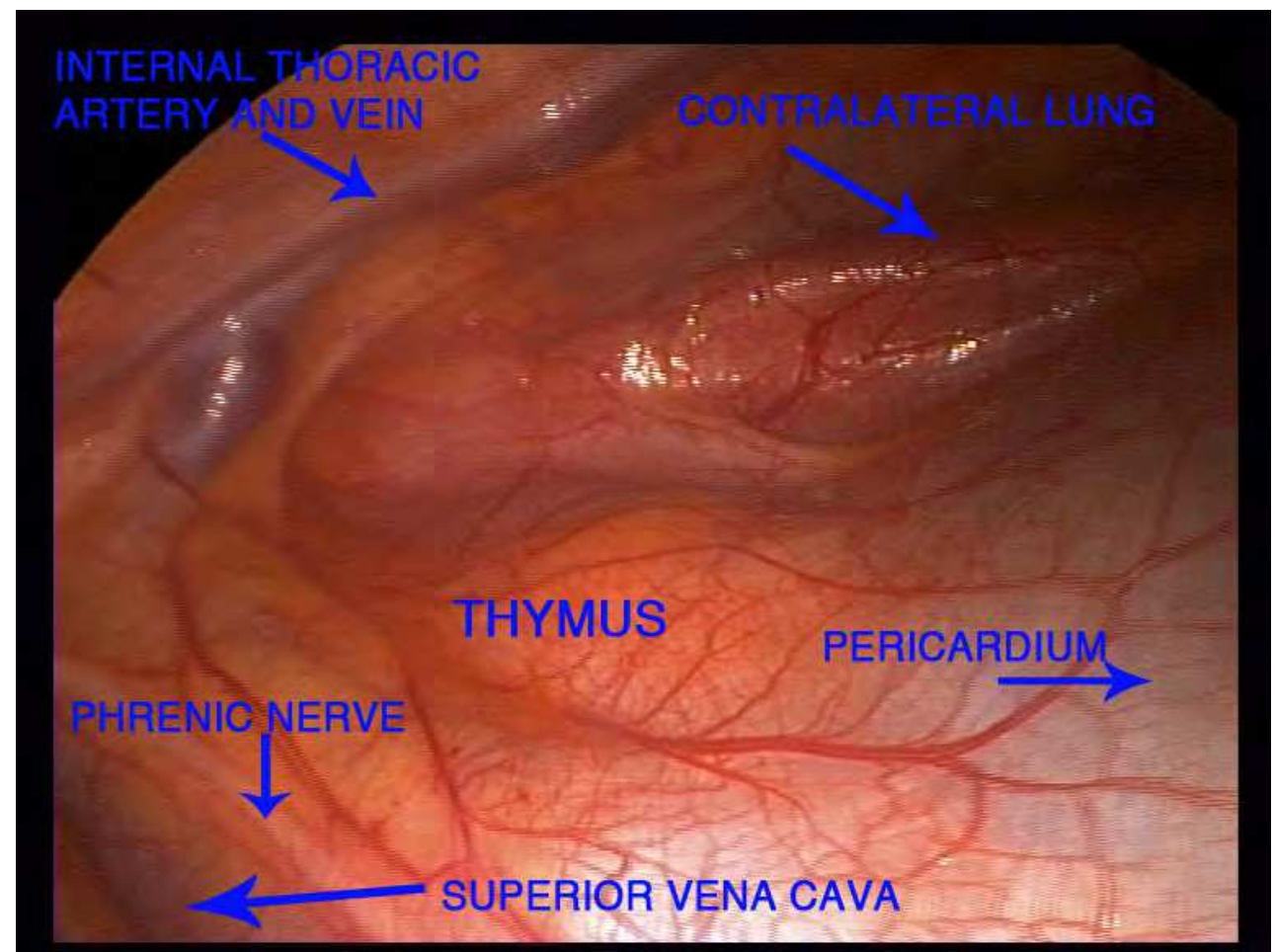

Fig. 3. Landmarks of the anterior mediastinum in thymectomy (right side approach) 


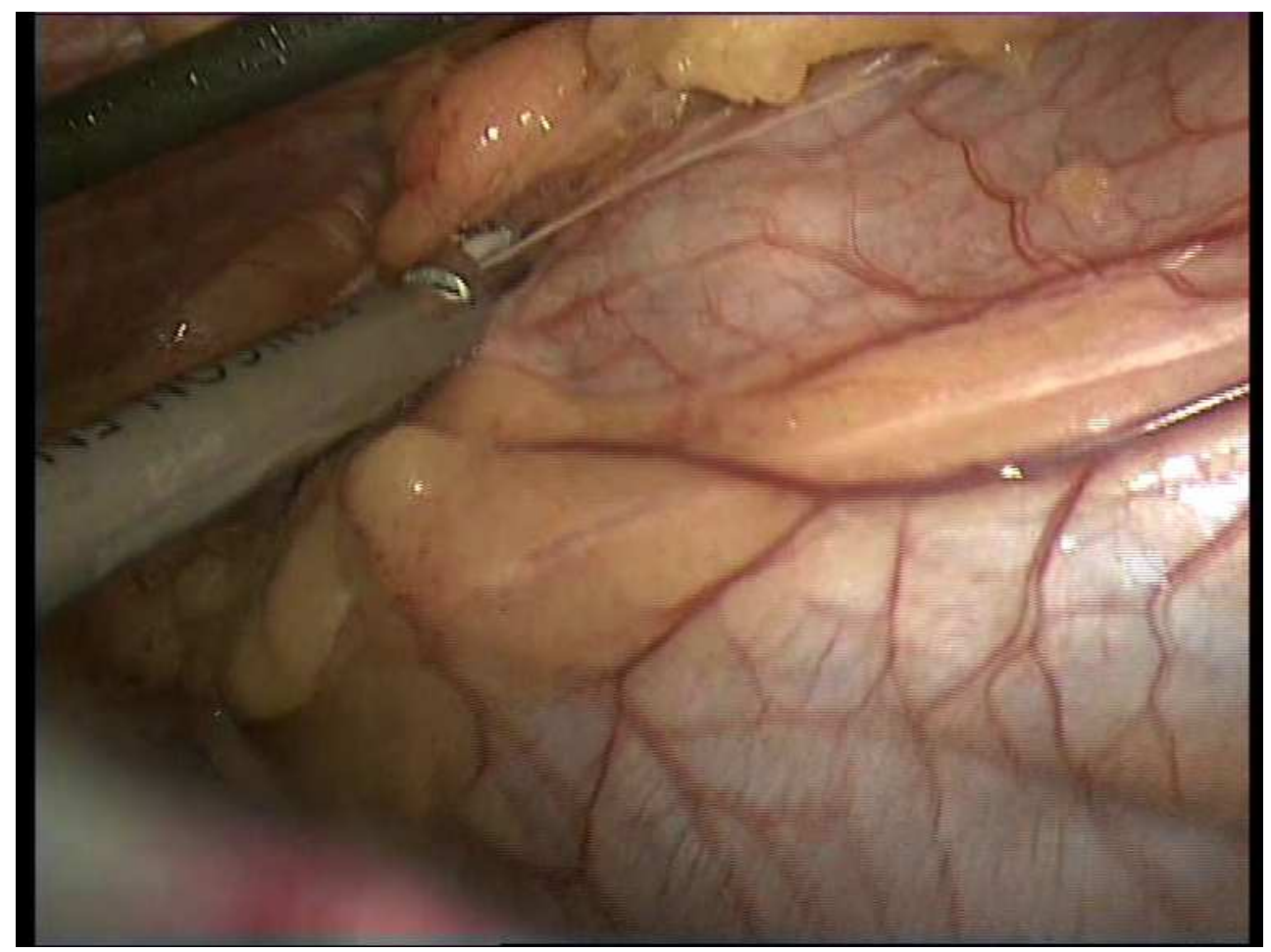

Fig. 4. Dissection of the left inferior thymus horn - beginning of the intervention

The dissection of the thymic tissue together with pericardial fat goes cephalad on the pericardial plane (fig5) overtaking the median line, to the right of the thymus gland. The contra-laterally mediastinal pleura is opened and the inferior right thymic horn and pericardial fatty tissue is dissected in the same manner (fig6). We continue to dissect anterior, retrosternal, the mediastinal pleura being open on the right side till the right mammary pedicle. The posterior dissection continues similar, the pericardium, the aortic arch, the left brachiocephalic vein, and the superior vena cava are visualized and cleaned of all fat tissue or thymus. The most difficult area to dissect is in the aortopulmonary window (fig 7) and the aortocaval groove (fig 8). At the superior pole, the dissection is performed in the anterior carotidal plane to the internal thoracic artery level. The left superior horn or some time both upper horns may occasionally pass behind, instead of in front of the brahiocephalic vein (fig 9). This anatomical variety is more difficult to be solved by thoracoscopic approach. We have to be aware of the vagus nerve ant left recurrent laryngeal nerve that goes close and dissect carefully inferior and posterior to the brahiocephalic vein and then superior, to free the cervical parts of the upper horns. Afterwards traction of the upper horns caudally permits the dissection of them behind the brahiocephalic vein, in order to visualize an eventual posterior thymus vein. 


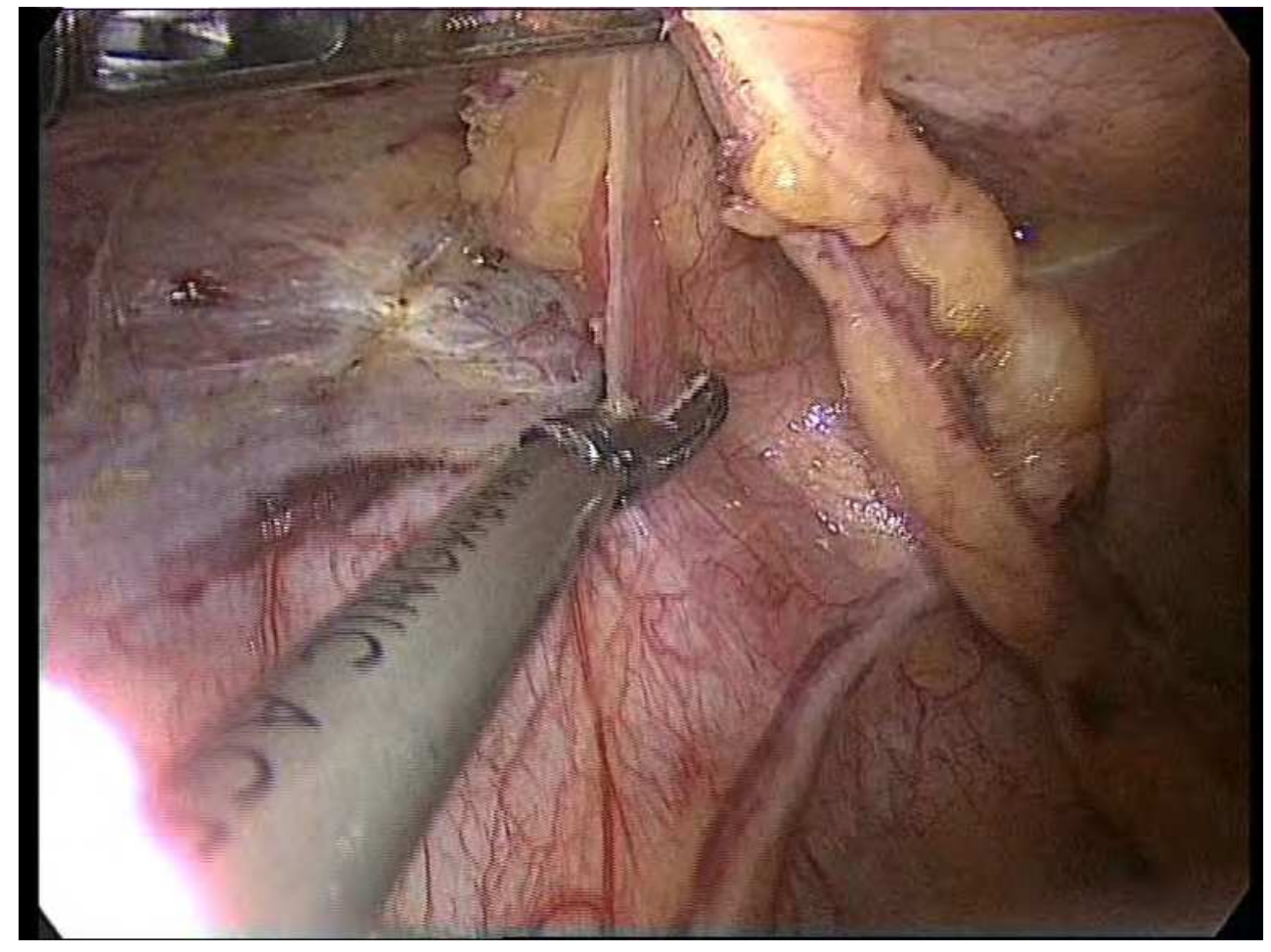

Fig. 5. Dissection in the pre-pericardial plane 


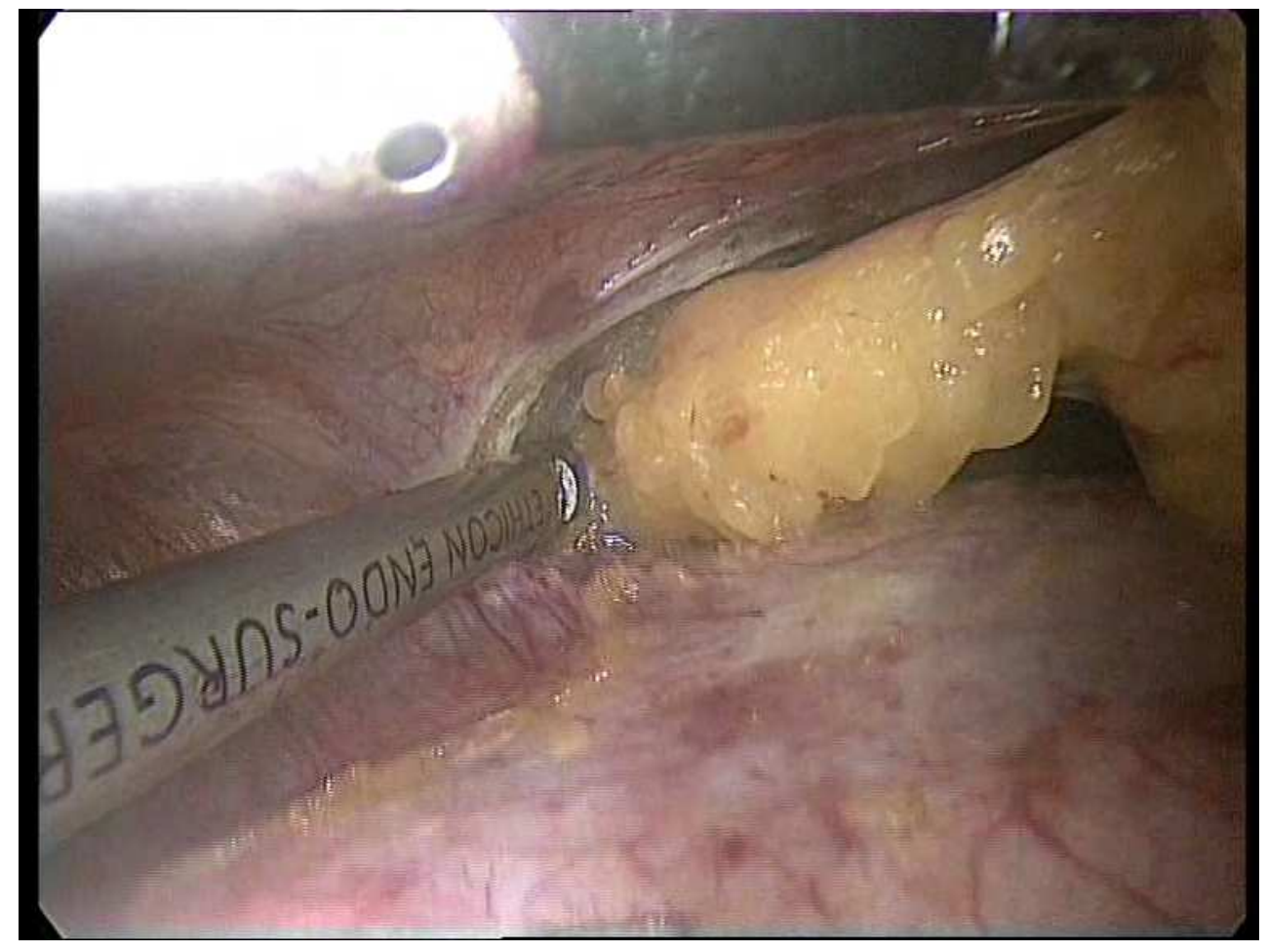

Fig. 6. Dissection of the contra-laterally inferior horn (left side approach) 


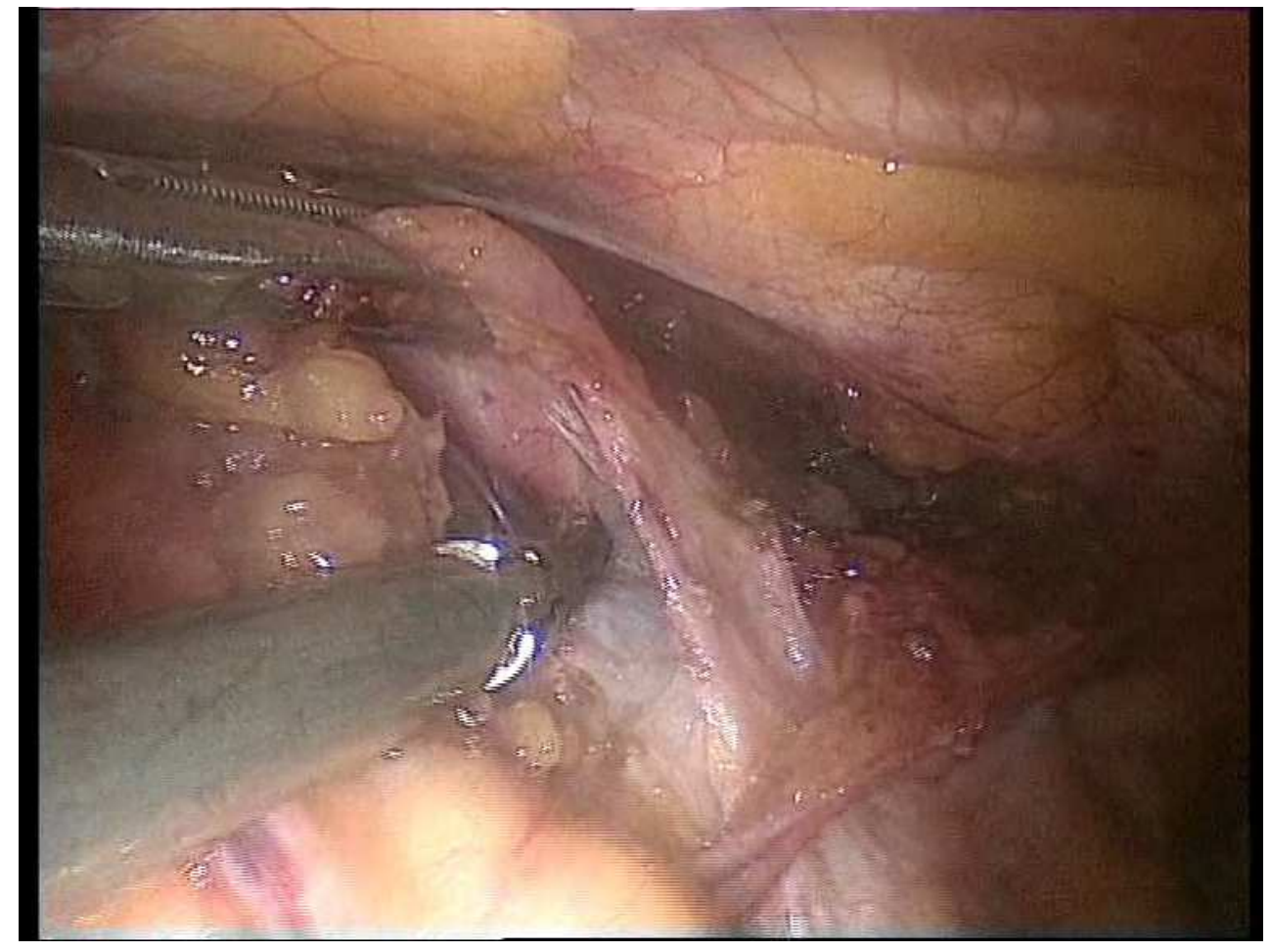

Fig. 7. Dissection of the aortopulmonary window 


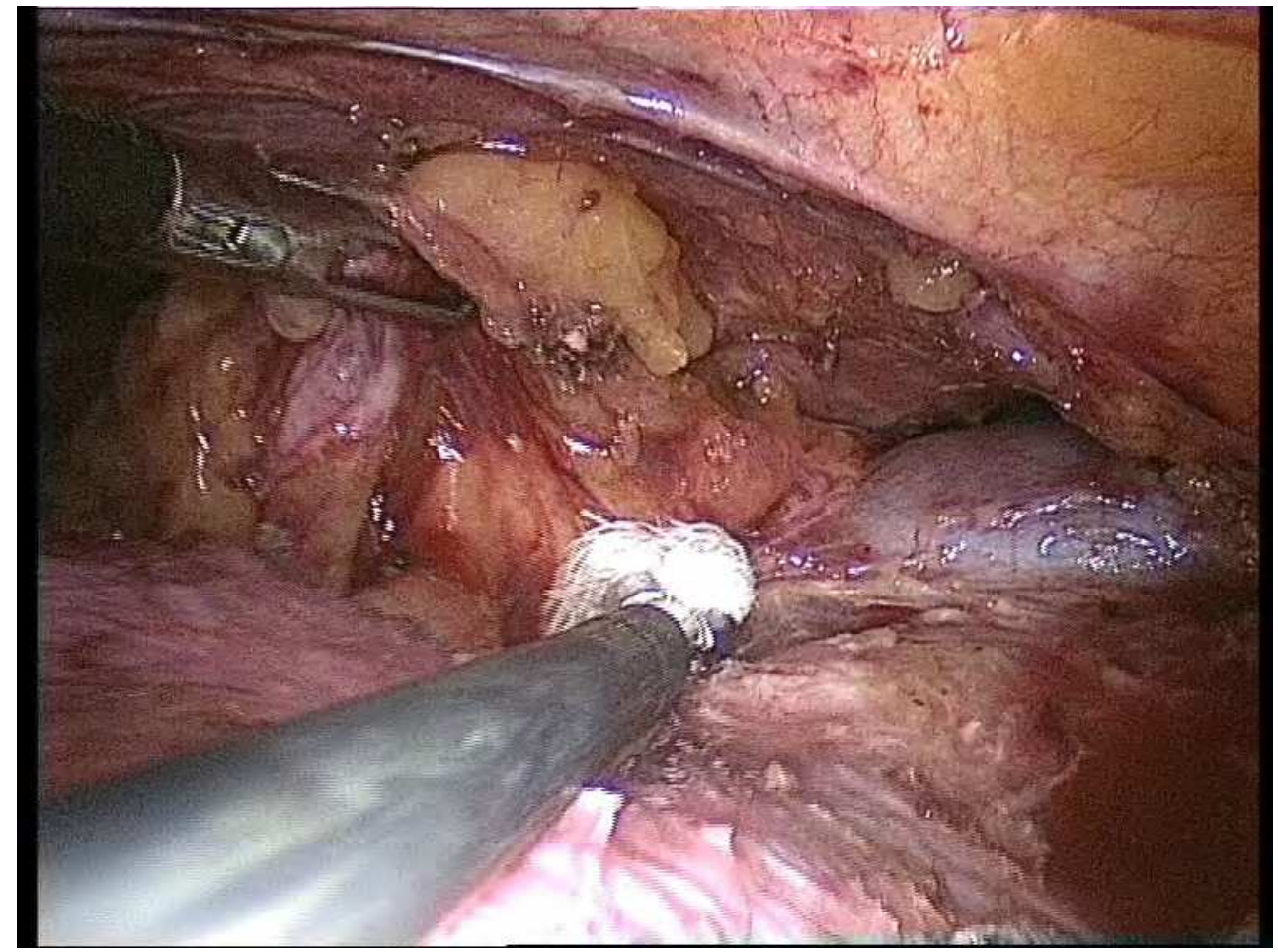

Fig. 8. Dissection of the aorto-caval groove

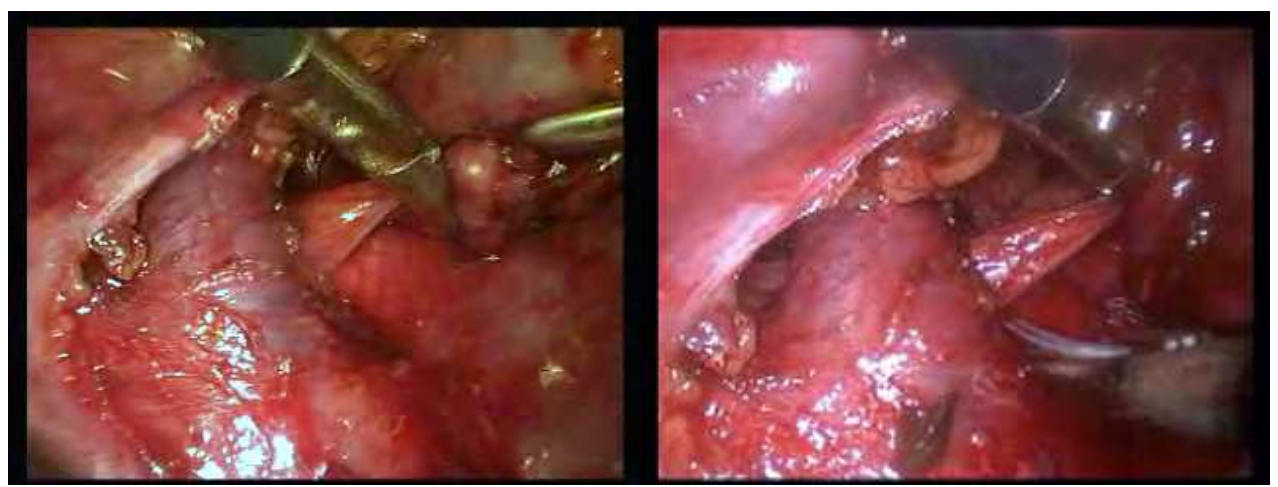

Fig. 9. Posterior upper right thymus horn dissection (right side approach)

The thymectomy ends with the identification of the superior part of the gland, the thyroidthymic ligament section, and freeing of the superior horns from the surrounding tissue. After dissecting the surrounding fascia and cutting the vessels that goes caudally from cervix, upper horns can be mobilized caudally by applying gentle traction (fig 10). Cervical skin transillumination is the indication that the cervical limit of the dissection has been reached. During the operation, we can visualize the superior, lateral, or medial arterial 
thymic pedicles. They are clipped and cut or ultrasonically coagulated (fig 11). Dissection of the thymic veins is very important. The veins are very short and enter directly into the left brachiocephalic vein. Tearing out such a pedicle may cause a hemorrhage, which is very difficult to correct thoracoscopically. Visualization of the right phrenic nerve is necessary to complete the dissection of thymus and fatty tissue (fig 12).

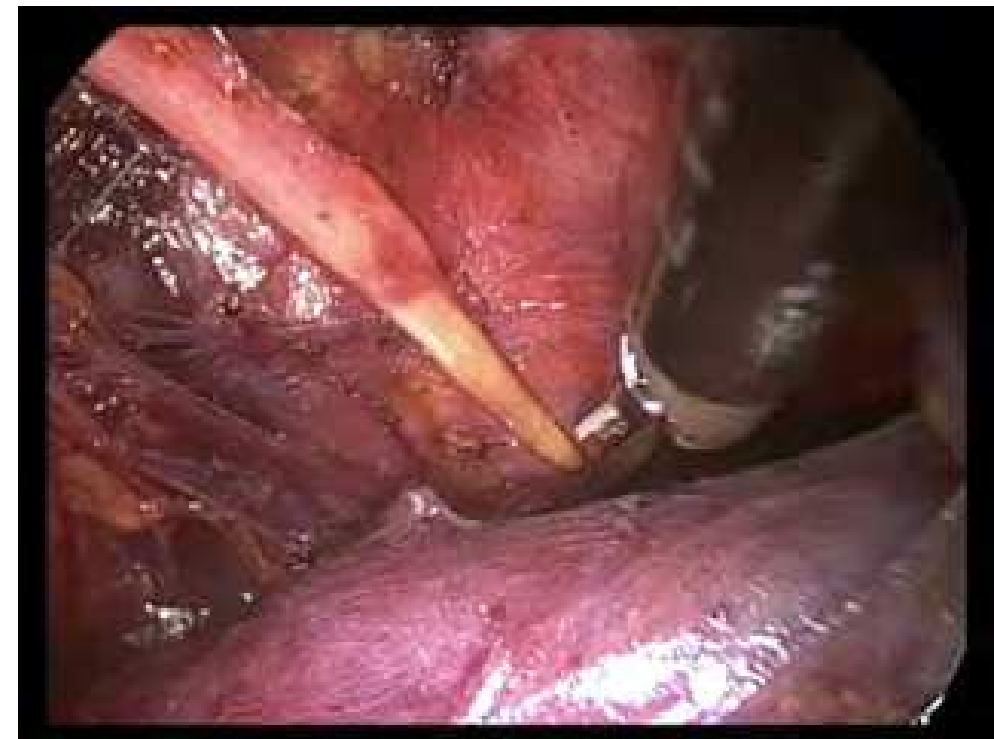

Fig. 10. Dissection of the upper left horn

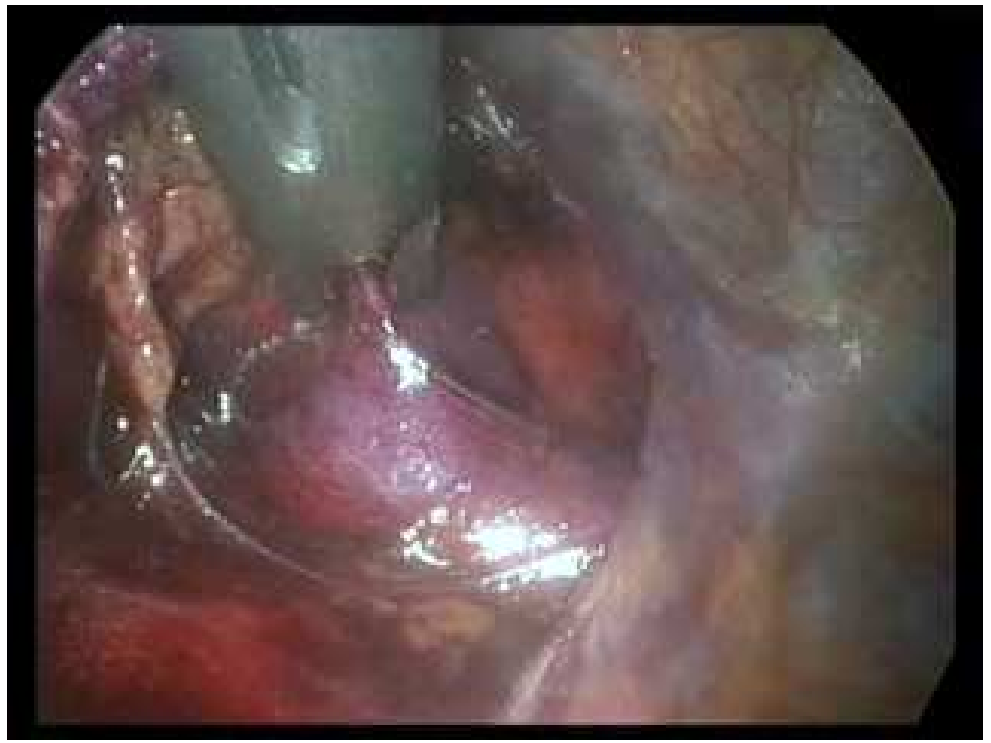

Fig. 11. Clipping the thymus vein 


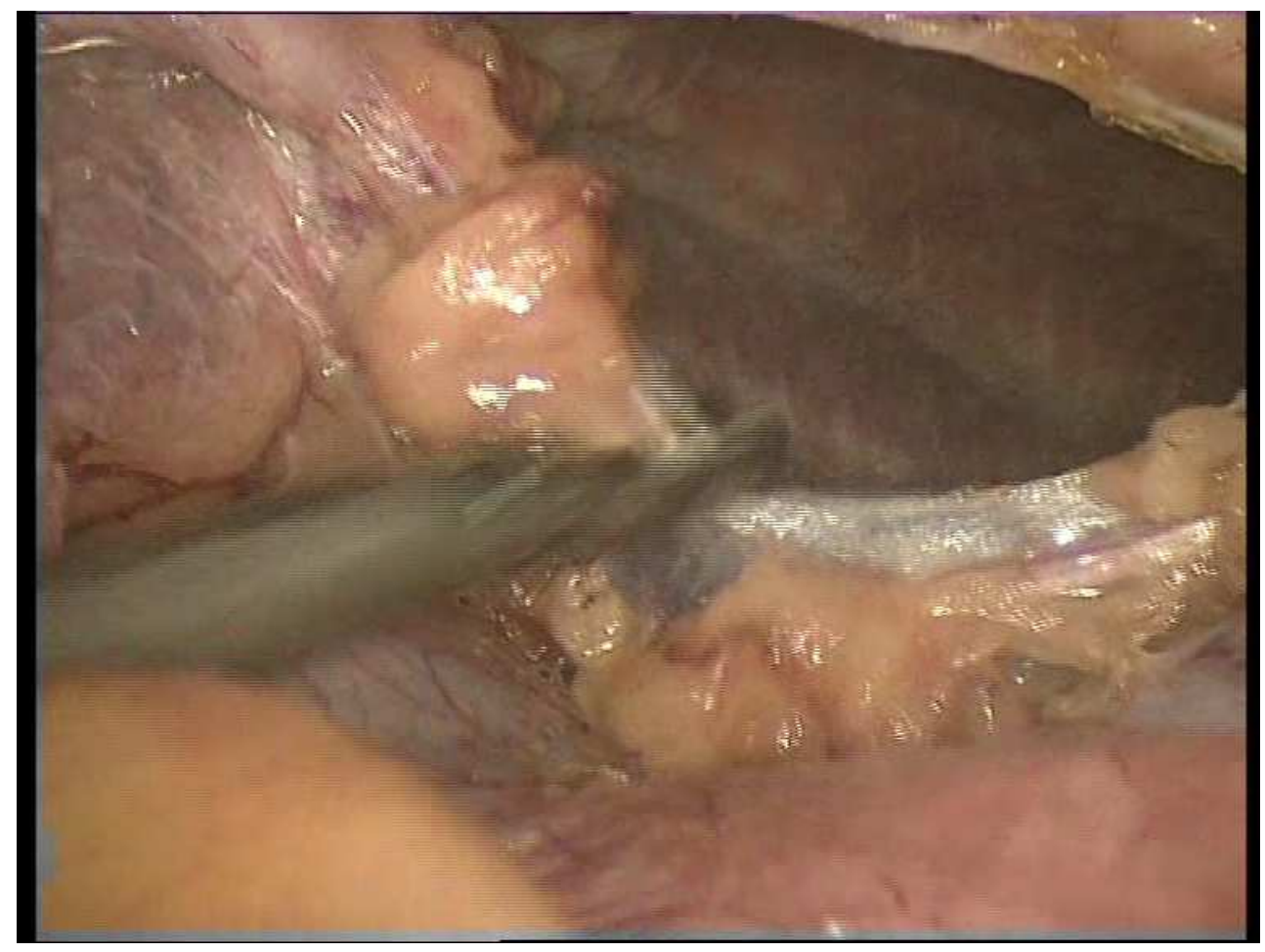

Fig 12. Visualization of the right phrenic nerve (left side approach)

We sometimes used a needle-scope camera that was inserted through the Veress needle in the contra lateral thorax to control the complete dissection (fig 13).

Thymus extraction is quite easily done by enlarging the hole of one of the trocar ports and bagging the piece before extracting it (fig 14). We prefer to introduce the bag at the beginning of the intervention, this way any small piece of thymus or fatty tissue could be bagged during dissection. 


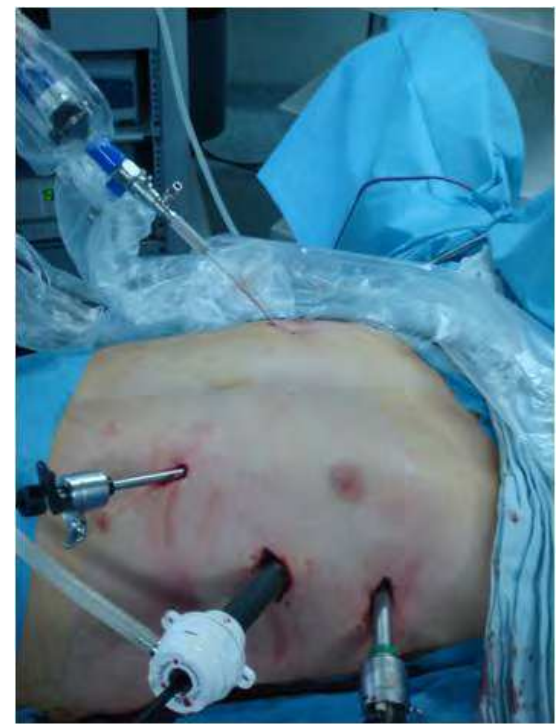

Fig. 13. Control of the complete dissection with a needle-scope camera that was inserted through the Veress needle in the contra lateral thorax

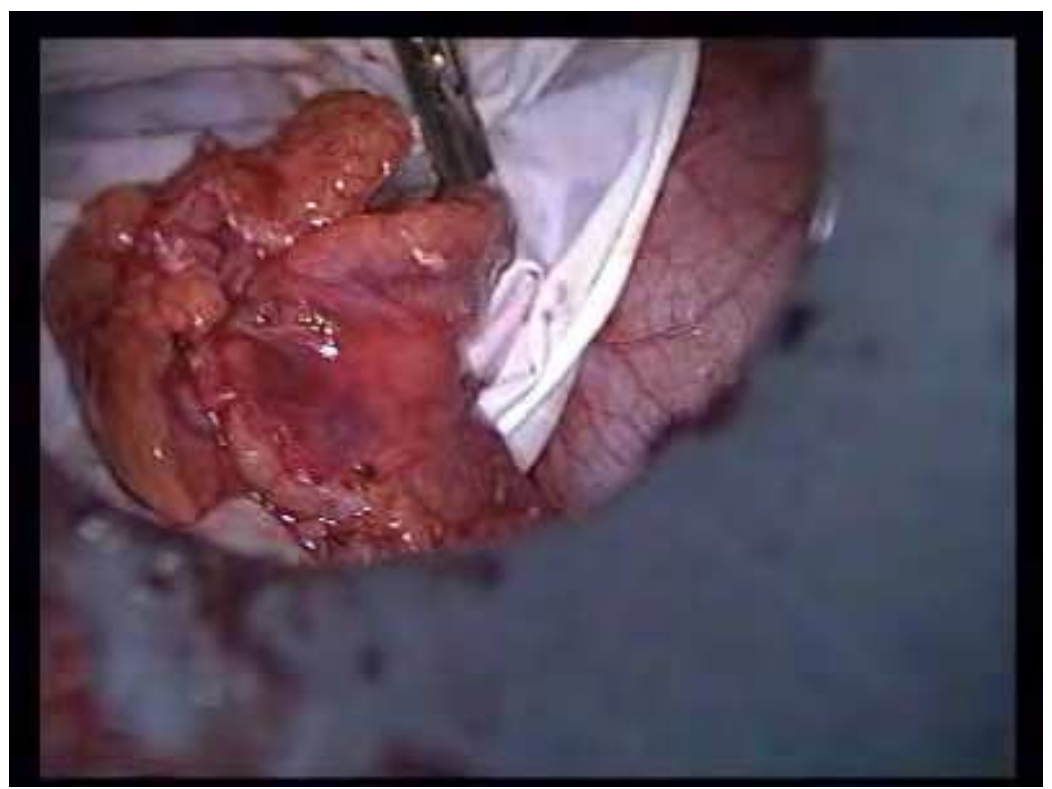

Fig. 14. Extractic the specimen in self-made bag

The operation ends with the thymic cavity inspection, which can detect possible remnant tissue (fig 15). Finally, we wash the cavity with warm saline. At the end of the operation one or two drains can be placed in the pleural cavity through the inferior trocar ports. 
Thoracoscopic thymectomy through the right side is performed in the same manner, the most difficult part of this approach being the aortopulmonary window(Ruckert et al. 2000, 18:735-736) and left inferior horn.

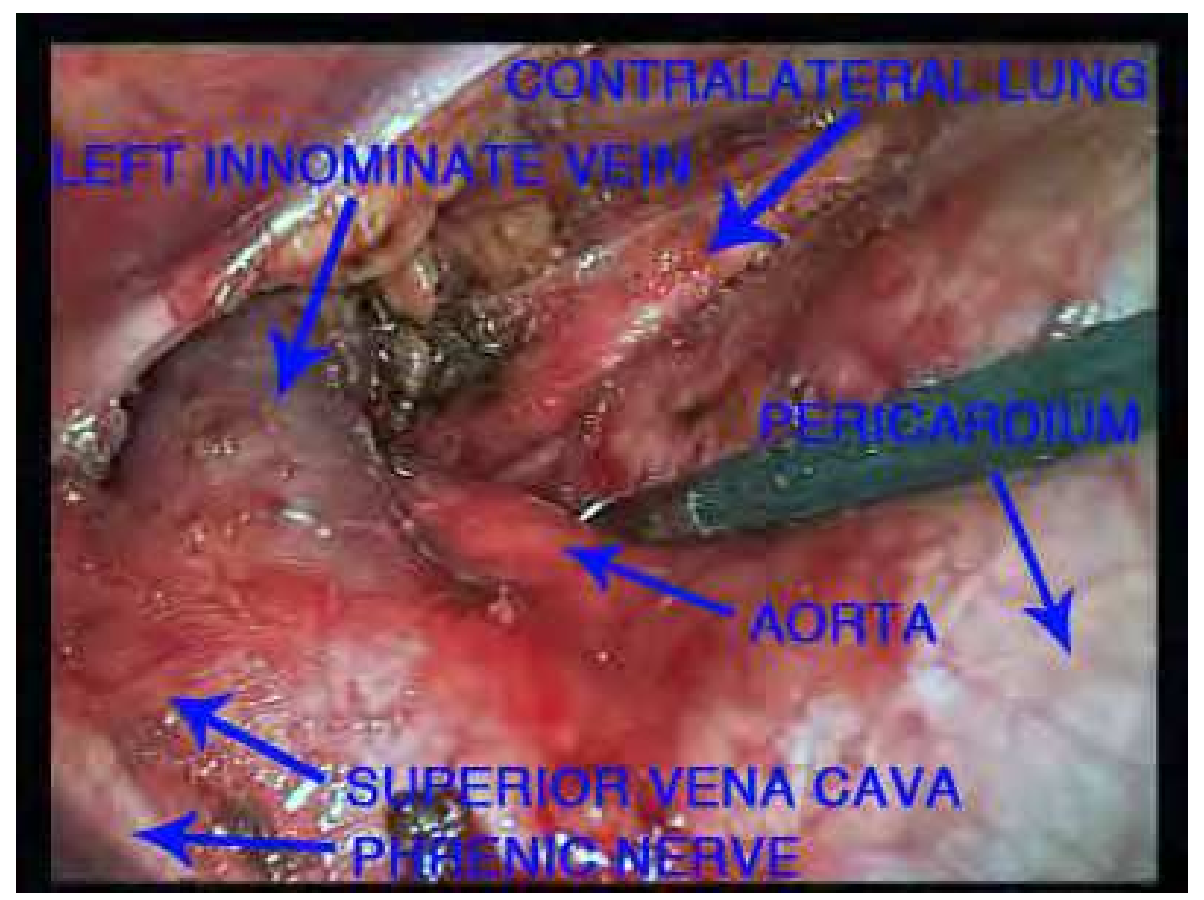

Fig 15. Landmarks of the anterior mediastinum at the end of thymectomy (right side approach)

Yim and colleagues(Yim 1997, 64:584-585) favor the right thoracoscopic approach because:

1. identification of the vena cava is a landmark for easier dissection of innominate vein,

2. the confluence of the innominate veins is easier to dissect by using a right approach,

3. ergonomically, it is easier for right-hand surgeons to dissect the thymus from inferior horns to upper horns with a right approach.

To this we would add that the right approach allows a better view in the cervical area. Irrespective of the patient's anatomic characteristics, every effort is made to perform a full removal of the thymic tissue by clearing the innominate vein and anterior pericardium from all mediastinal fat. We believe a left-side approach facilitates the procedure because most of the mediastinal fat is located on the left side of the anterior mediastinum. The use of a $30^{\circ}$ endoscope (Karl Storz-Endoscopy) provides significant help. Although we share the opinion of Mineo and colleagues(Mineo, Pompeo, and Ambrogi 1997, 114:516-517) that thymectomy can be performed by either a left-side or a right-side approach, we believe the left-side approach has some advantages. In our experience, the dissection maneuvers are safer when performed on the left side because the right phrenic nerve is situated outside the surgical field, thus reducing the risk of an incidental lesion. It is also easier to perform a dissection of 
the right side of the thymus by a left approach than a dissection of the left side of the thymus by right approach, especially for the aortopulmonary window.

\section{Personal results}

Since April 1999, a thoracoscopic approach has been used in all patients admitted in the Department of General Surgery and Liver Transplantation of Fundeni Clinical Institute with either nonthymomatous myasthenia gravis or stage I and IIa Masaoka thymomas. There have been 300 patients with nontumoral myasthenia gravis (NTMG) that have suffered an extended thoracoscopic thymectomy in our center between April 1998 and April 2011.

We considered that favourable outcomes requires highly coordinated teamwork involving a strong collaboration between neurologists, surgeons, and anesthesiologists in making appropriate decisions on selection of patients, therapeutic options, and timing of surgery. All of the patients received specific treatment for at least 3 months before surgery in the Department of Neurology of our institute. Patients were considered suitable for a surgical procedure only when evidence showed good treatment tolerance and a stable quantitative myasthenia gravis (QMG) score of at least 10 points. We did not operate patients with pure ocular myasthenia gravis because we considered that the indication for thymectomy in ocular myasthenia gravis remained controversial. We did not operate patients with age over 60 years.

Treatment, morbidity, mortality, and postinterventional status at follow-up were also assessed according to the MGFA Recommendations for Clinical Research Standards, QMG scores being the most valuable tool in quantitative evaluation of clinical improvement or remission analysis. CSR was used as the end point for the evaluation of the efficacy and prognostic factors. Patients were considered to be in complete stable remission status if they exhibited no symptoms of MG for at least one year and had received no therapy for MG during that time.

A left thoracoscopic approach was used for $29 \%$ of the patients and a right thoracoscopic approach for $71 \%$ of the patients. Decision to use the right-side or left-side approach was considered in relation with the CT aspect of each patient's thymus. Extensive dissection in the region of the thyroid and lateral neck, through a separate collar incision, was not routinely performed. The low probability of finding aberrant thymic remnants in these locations did not justify this approach as a standard procedure. Minicervicotomies were performed on 7 patients, due to cervical extensions of the thymus. There were no conversions to open thymectomy. The mean operative time was of $80+/-45 \mathrm{~min}$. There was zero mortality and morbidity was observed in 14 patients (4.66\%): 10 patients previously reported(Tomulescu et al. 2006, 82:1003-1007) (severe postoperative myasthenia crisis in 1 patient who needed mechanical ventilation for 5 days, 2 with contralateral pneumothorax after drain removal, 3 with hemothorax that required emergent reintervention, and 6 with prolonged pleural drainage) and 2 patients with postoperative pneumonia.

The mean length of hospitalization was 2.1 days (range: 2-6 days).

Evaluating the post-interventional status according to the MGFA recommendations for Clinical Research Standards complete stabile remission (CSR) have been obtained in $62 \%$ (186 patients), pharmacologic remission (PR) in 8\% (24 patients), minimal manifestation $(\mathrm{MM})$ in $15 \%$ (45 patients), non changed $(\mathrm{N})$ in 10\% (30 patients), worse (W) in 1\% (3 patients) and exacerbation (E) - patients who have fulfilled the criteria of CSR, PR, or MM 
but subsequently developed clinical findings greater than permitted by these criteria - in $4 \%$ (12 patients).

\section{Conclusions}

Unilaterally extended thoracoscopic thymectomy is a technically demanding procedure that requires expertise in extended thymectomy and in advanced minimally invasive techniques. The right side, the left side or even bilateral approach should be chosen in relation with the method the surgeon is more comfortable and from which best results (morbidity, mortality, completeness of thymectomy) should be expected.

The maximal thymectomy should remain the benchmark against which other thymectomy techniques are measured (whether or not it is the surgical technique of choice) (Jaretzki, III, Barohn, Ernstoff, Kaminski, Keesey, Penn, and Sanders 2000, 70:327-334;Jaretzki, III and Wolff 1988, 96:711-716; Sonett and Jaretzki, III 2008, 1132:315-328) but we consider that with no mortality, low morbidity, comparable CSR and PR, better cosmetic and pulmonary function-sparing effect, superior compliance from the patients and neurologists with a higher rate acceptance of surgical treatment, this minimally invasive approach could become the best first solution in the multimodal treatment of myasthenia gravis.

\section{References}

Almon RR, and Appel SH. 1976. Serum acetylcholine-receptor antibodies in myasthenia gravis. Ann. N. Y. Acad. Sci. 274: 235-243.

Beekman R, Kuks JB, and Oosterhuis HJ. 1997. Myasthenia gravis: diagnosis and follow-up of 100 consecutive patients. J. Neurol. 244 (2): 112-118.

Buckingham JM, Howard FM, Jr., Bernatz PE, Payne WS, Harrison EG, Jr., O'Brien PC, and Weiland LH. 1976. The value of thymectomy in myasthenia gravis: a computerassisted matched study. Ann. Surg. 184 (4): 453-458.

Bulkley GB, Bass KN, Stephenson GR, Diener-West M, George S, Reilly PA, Baker RR, and Drachman DB. 1997. Extended cervicomediastinal thymectomy in the integrated management of myasthenia gravis. Ann. Surg. 226 (3): 324-334.

Carlsson B, Wallin J, Pirskanen R, Matell G, and Smith CI. 1990. Different HLA DR-DQ associations in subgroups of idiopathic myasthenia gravis. Immunogenetics 31 (5-6): 285-290.

Drachman DB. 1994. Myasthenia gravis. N. Engl. J. Med. 330 (25): 1797-1810.

Evoli A, Tonali PA, Padua L, Monaco ML, Scuderi F, Batocchi AP, Marino M, and Bartoccioni E. 2003. Clinical correlates with anti-MuSK antibodies in generalized seronegative myasthenia gravis. Brain 126 (Pt 10): 2304-2311.

Gronseth GS, and Barohn RJ. 2000. Practice parameter: thymectomy for autoimmune myasthenia gravis (an evidence-based review): report of the Quality Standards Subcommittee of the American Academy of Neurology. Neurology 55 (1): 7-15.

Guillermo GR, Tellez-Zenteno JF, Weder-Cisneros N, Mimenza A, Estanol B, Remes-Troche JM, and Cantu-Brito C. 2004. Response of thymectomy: clinical and pathological characteristics among seronegative and seropositive myasthenia gravis patients. Acta Neurol. Scand. 109 (3): 217-221.

Hughes BW, Moro De Casillas ML, and Kaminski HJ. 2004. Pathophysiology of myasthenia gravis. Semin. Neurol. 24 (1): 21-30. 
Jaretzki A, III, Barohn RJ, Ernstoff RM, Kaminski HJ, Keesey JC, Penn AS, and Sanders DB. 2000. Myasthenia gravis: recommendations for clinical research standards. Task Force of the Medical Scientific Advisory Board of the Myasthenia Gravis Foundation of America. Ann. Thorac. Surg. 70 (1): 327-334.

Jaretzki A, Steinglass KM, and Sonett JR. 2004. Thymectomy in the management of myasthenia gravis. Semin. Neurol. 24 (1): 49-62.

Jaretzki A, III, and Wolff M. 1988. "Maximal" thymectomy for myasthenia gravis. Surgical anatomy and operative technique. J. Thorac. Cardiovasc. Surg. 96 (5): 711-716.

Keesey JC. 2004. A history of treatments for myasthenia gravis. Semin. Neurol. 24 (1): 5-16.

Leite MI, Jones M, Strobel P, Marx A, Gold R, Niks E, Verschuuren JJ, Berrih-Aknin S, Scaravilli F, Canelhas A, Morgan BP, Vincent A, and Willcox N. 2007. Myasthenia gravis thymus: complement vulnerability of epithelial and myoid cells, complement attack on them, and correlations with autoantibody status. Am. J. Pathol. 171 (3): 893-905.

Lennon VA, Lindstrom JM, and Seybold ME. 1976. Experimental autoimmune myasthenia gravis: cellular and humoral immune responses. Ann. N. Y. Acad. Sci. 274: 283-299.

Mineo TC, Pompeo E, and Ambrogi V. 1997. Video-assisted thoracoscopic thymectomy: from the right or from the left? J. Thorac. Cardiovasc. Surg. 114 (3): 516-517.

Navaneetham D, Penn AS, Howard JF, Jr., and Conti-Fine BM. 2001. Human thymuses express incomplete sets of muscle acetylcholine receptor subunit transcripts that seldom include the delta subunit. Muscle Nerve 24 (2): 203-210.

Niks EH, Kuks JB, Roep BO, Haasnoot GW, Verduijn W, Ballieux BE, De Baets MH, Vincent A, and Verschuuren JJ. 2006. Strong association of MuSK antibody-positive myasthenia gravis and HLA-DR14-DQ5. Neurology 66 (11): 1772-1774.

Romi F, Gilhus NE, and Aarli JA. 2006. Myasthenia gravis: disease severity and prognosis. Acta Neurol. Scand. Suppl 183: 24-25.

Rubin JW. 2006. Invited commentary. Ann. Thorac. Surg. 82 (3): 1007-1008.

Ruckert JC, Czyzewski D, Pest S, and Muller JM. 2000. Radicality of thoracoscopic thymectomy--an anatomical study. Eur. J. Cardiothorac. Surg. 18 (6): 735-736.

Schonbeck S, Padberg F, Hohlfeld R, and Wekerle H. 1992. Transplantation of thymic autoimmune microenvironment to severe combined immunodeficiency mice. A new model of myasthenia gravis. J. Clin. Invest 90 (1): 245-250.

Simpson JA. 1982. Myasthenia gravis. Practitioner 226 (1368): 1045-1050.

Sommer N, Tackenberg B, and Hohlfeld R. 2008. The immunopathogenesis of myasthenia gravis. Handb. Clin. Neurol. 91: 169-212.

Sommer N, Willcox N, Harcourt GC, and Newsom-Davis J. 1990. Myasthenic thymus and thymoma are selectively enriched in acetylcholine receptor-reactive T cells. Ann. Neurol. 28 (3): 312-319.

Sonett JR, and Jaretzki A, III. 2008. Thymectomy for nonthymomatous myasthenia gravis: a critical analysis. Ann. N. Y. Acad. Sci. 1132: 315-328.

Tomulescu V, Ion V, Kosa A, Sgarbura O, and Popescu I. 2006. Thoracoscopic thymectomy mid-term results. Ann. Thorac. Surg. 82 (3): 1003-1007.

Toyka KV, and Gold R. 2007. Treatment of myasthenia gravis. Schweiz Arch Neurol Psychiatr 158: 309-321.

Yim AP. 1997. Thoracoscopic thymectomy: which side to approach? Ann. Thorac. Surg. 64 (2): 584-585. 


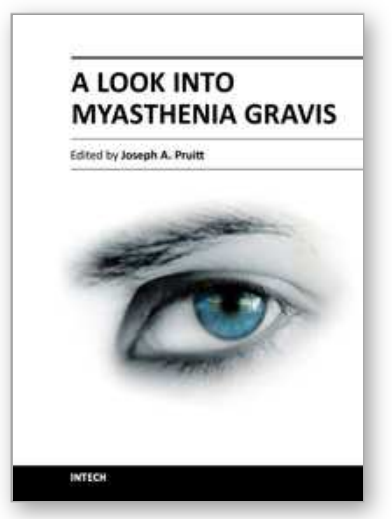

\author{
A Look into Myasthenia Gravis \\ Edited by Dr. Joseph A. Pruitt
}

ISBN 978-953-307-821-2

Hard cover, 106 pages

Publisher InTech

Published online 20, January, 2012

Published in print edition January, 2012

Myasthenia gravis is presently an incurable antibody-mediated autoimmune disorder characterized by generalized voluntary skeletal muscle weakness. The cause of the weakness is a defect at the neuromuscular junction level, in which autoimmune antibodies block the receptors responsible for initiating muscular contraction. Literally translated from its Latin and Greek etymological roots, myasthenia gravis means "grave muscle weakness". Fortunately, advances in modern medicine have resulted in a reduction of the truly "grave" outcomes for those inflicted but, without a cure, the gravity surrounding the disease remains

\title{
How to reference
}

In order to correctly reference this scholarly work, feel free to copy and paste the following:

Victor Tomulescu (2012). Unilaterally Extended Thoracoscopic Thymectomy: The Right Side or the Left Side Approach, A Look into Myasthenia Gravis, Dr. Joseph A. Pruitt (Ed.), ISBN: 978-953-307-821-2, InTech, Available from: http://www.intechopen.com/books/a-look-into-myasthenia-gravis/unilaterally-extendedthoracoscopic-thymectomy-the-right-side-or-the-left-side-approach

\section{INTECH}

open science | open minds

\section{InTech Europe}

University Campus STeP Ri

Slavka Krautzeka 83/A

51000 Rijeka, Croatia

Phone: +385 (51) 770447

Fax: +385 (51) 686166

www.intechopen.com

\section{InTech China}

Unit 405, Office Block, Hotel Equatorial Shanghai

No.65, Yan An Road (West), Shanghai, 200040, China

中国上海市延安西路65号上海国际贵都大饭店办公楼 405 单元

Phone: +86-21-62489820

Fax: +86-21-62489821 
(C) 2012 The Author(s). Licensee IntechOpen. This is an open access article distributed under the terms of the Creative Commons Attribution 3.0 License, which permits unrestricted use, distribution, and reproduction in any medium, provided the original work is properly cited. 